\title{
What IS AN ADEQUATE STANDARD OF LIVING DURING RETIREMENT?
}

\author{
Johannes Binswanger \\ Daniel Schunk
}




\title{
What Is an Adequate Standard of Living during Retirement?*
}

\author{
Johannes Binswanger ${ }^{\dagger}$ \\ Daniel Schunk ${ }^{\ddagger}$
}

September 25, 2008

\begin{abstract}
Many economists and policy-makers argue that households do not save enough to maintain an adequate standard of living during retirement. However, there is no consensus on the answer to the underlying question what this standard should be, despite the fact that it is crucial for the design of saving incentives and pension reforms. We address this question with a survey, individually tailored to each respondent's financial situation, conducted both in the U.S. and the Netherlands. Key findings are that adequate levels of retirement spending exceed 70 percent of working life spending, and minimum acceptable replacement rates depend strongly on income.
\end{abstract}

Key words: Life cycle preferences, pension reform, replacement rates, retirement saving.

JEL classification: D91, H55.

${ }^{*}$ We would like to thank Arthur van Soest for very helpful support. We are also grateful to Yvonne Adema, James Banks, Rotraut Binswanger, Jan Boone, Axel Börsch-Supan, Katie Carman, Norma Coe, Jeffrey Dominitz, Josef Falkinger, Ernst Fehr, Alia Gizatulina, Sally Gschwend, Eline van der Heijden, Hendrik Jürges, Arie Kapteyn, Miles Kimball, Annamaria Lusardi, Olivia Mitchell, Hans-Theo Normann, Charles Noussair, Jan Potters, Maarten van Rooij, Claudia Sahm, Matthew Shapiro, Jonathan Skinner, Karen van der Wiel, Joachim Winter, and to participants at the MESS workshop, at Netspar workshops and seminar participants at Tilburg University and the University of Muenster for astute comments on this paper. Thanks also to Vera Toepoel from CentERdata and to Bas Weerman from RAND for programming our questionnaire and for valuable support, as well as to many other colleagues and friends for valuable feedback on our questionnaire. Financial support from CentER and Netspar is gratefully acknowledged.

$\dagger$ Corresponding Author; Department of Economics, CentER and Netspar, Tilburg University, P.O. Box 90153, 5000 LE Tilburg, The Netherlands; j.binswanger@uvt.nl.

${ }^{\ddagger}$ Institute for Empirical Research in Economics (IEW), University of Zurich, 8006 Zurich, Switzerland; dschunk@iew.uzh.ch 


\section{Introduction}

What level of spending during retirement do people consider desirable, given their lifetime budget constraints? How does this level compare to spending during working life? Is there a minimum level of retirement spending which people want to maintain at all costs? How much risk are individuals ready to bear in exchange for a higher expected standard of living during retirement? Finally, how do desired standards of living during retirement vary across the population?

The answers to these questions provide a sound benchmark level for an adequate standard of living during retirement and are thus important for three policy issues. First, such a benchmark level allows us to address a concern expressed by many economists and policy-makers: whether people are adequately prepared for retirement 1 Second, such a benchmark may serve as advice to individuals who find determining an adequate level of retirement savings themselves difficult. Third, such a benchmark is highly informative for the many countries around the globe that are currently considering reforming their pension systems, since any pension reform plan requires information about adequate benefit levels.

Several approaches for addressing the opening questions of this paper already exist. One approach is to assume that a constant relative risk aversion (CRRA) utility function can approximate individuals' preferences. Making specific assumptions about the parameters of this function as well as about other relevant variables such as interest rates and equity returns allows for calibrating optimal consumption choices during old age and during working life. According to this approach, which we dub the calibration approach, actual observed choices are considered adequate if they come sufficiently close to these calibrated choices.2 A second approach to operationalizing the notion of an adequate level of retirement spending is to refer to certain benchmark replacement rates relating to either income or spending. Third, one may refer to poverty thresholds.

\footnotetext{
${ }^{1}$ See Bernheim (1992), Bernheim et al. (2000), Lusardi and Mitchell (2007), Munnell et al. (2006), Skinner (2007), and Thaler (1994).

${ }^{2}$ See Scholz et al. (2006) for an impressive application of this methodology.
} 
None of these approaches is without problems. Clearly, any a priori chosen benchmark for a replacement rate, such as 70 or 80 percent, is ad hoc. Furthermore, in the presence of risk, it is not clear whether such a benchmark refers to the expected value or some other point in the distribution of possibly realized replacement rates. Concerning poverty thresholds, there are several different concepts of these thresholds, and the exact definition of the poverty line is necessarily somewhat arbitrary. While of obvious interest and conceptually very elegant, the preference-based calibration approach is also fraught with problems. How confident can we feel that individuals' true preferences can be approximated by a CRRA utility function with a coefficient of relative risk aversion of, say, 3? Why not 12 ? 3 How confident can we feel about the assumption that, for CRRA preferences, the coefficient of relative risk aversion is equal to the inverse of the intertemporal elasticity of substitution? Furthermore, how large is the bias introduced by not accounting for the complementarity or substitutability between leisure and consumption? And if we were to take this into account, how should we calibrate this trade-off? There are a plethora of questions and we still know only very little about their answers.

It may seem that the problems of the calibration approach could be avoided by a revealed preference approach. This would entail an econometric analysis of individuals' observed retirement preparation choices which, in turn, would allow for inference of their preferences, such as the coefficient of relative risk aversion. However, an inherent problem with this procedure is that people's actual retirement preparation choices may not be in their best self-interest. This may be due to the fact that individuals simply adopt defaults (Beshears et al., 2006), lack the willpower to save sufficiently (Thaler, 1994), or lack financial literacy (Lusardi and Mitchell, 2007; van Rooij et al., 2007a).4 In fact, as is demonstrated by Skinner (2007), the determination of an appropriate savings plan that implements a given life cycle consumption profile is highly complex. As a result, inferring

\footnotetext{
${ }^{3}$ As put by Poterba et al. (2003), "within the framework of parametric CRRA utility functions, there is little consensus on the 'correct' value of the relative risk aversion coefficient" (p. 26).

${ }^{4}$ See Beshears et al. (2008) for a more complete discussion.
} 
individuals' true preferences from their observed retirement preparation choices might be inappropriate. Furthermore, inferring people's true preferences from their actual choices would be difficult, even in the absence of this concern, since the actual choices may be constrained by the presence of a mandatory pension system. 5

The novel approach we pursue in this paper is to address the questions raised in the first paragraph by means of a specifically designed internet survey module which we conduct with the American Life Panel (ALP) at RAND in the U.S., and with the CentERpanel (CP) in the Netherlands. The U.S. embodies a country where individuals bear a substantial amount of responsibility for their own retirement preparation, while the Netherlands are a country with a typical European-style welfare state and a pension system that offers generous replacement rates. In particular, the after-tax income replacement rate for an average earner amounts to about 85 percent in the Netherlands. In contrast, it amounts to only about 50 percent in the U.S. (OECD, 2007). It is therefore of interest to investigate whether notions of an adequate standard of living during retirement differ across such contrasting institutional setups, and if so to what degree.

Our survey approach is further inspired by the idea that, in a liberal society, it would be a priori desirable to base any notion of an adequate standard of living during retirement on individuals' own views. As discussed above, we have good reasons for believing that people may not be technically able to implement their most preferred consumption profile over the life cycle. However, this does clearly not imply that people do not know what they want. In order to avoid any premature paternalism, we therefore should not prematurely discard the idea that people may in principle know what consumption profile they find desirable (Beshears et al., 2008) 6

\footnotetext{
${ }^{5}$ This is a particular concern for many European countries whose pension systems offer relatively high replacement rates (see OECD, 2007).

${ }^{6}$ An example may help to make our argument clearer. Many people would not be able to construct their preferred car. Nevertheless, people may know what car they like. In a similar way, people may not be able to technically implement the financial choices that lead to, say, a spending replacement rate of 70 percent. But this may not imply that individuals do not have meaningful preferences over intertemporal consumption streams.
} 
Two features of our approach to elicit preferences over retirement spending profiles stand out. First, we go to great length to make all our survey questions as simple and as meaningful to respondents as possible. Specifically, we tailor the survey questions individually to each respondent's financial situation, based on prior information about variables such as total household income. Tailoring the questions to each respondent's own financial situation reduces the cognitive load and makes the questions meaningful in the context of the respondent's personal situation. Furthermore, none of our questions requires respondents to understand any technical aspects of retirement preparation such as the effects of compound interest and inflation. Second, three types of observations provide evidence that our survey indeed yields useful information about people's life cycle preferences: (i) This evidence comes from responses to feedback questions which we ask at the end of the survey; (ii), we include various randomization treatments and find that they do not affect response behavior in any way; and (iii), there are highly meaningful relationships between respondents' choices and socioeconomic variables.

Our main findings are as follows. First, neglecting any risk associated with retirement spending, we find that ex-ante desirable ratios of old age to working-life spending exceed 70 percent. This applies to both the U.S. and the Netherlands. Second, we investigate the lower limits on old age spending below which individuals would not want to fall in any case. We use information on these lower limits to calibrate minimum income replacement rates for each income quintile. For the U.S., these minimum replacement rates amount to about 100 percent for respondents in the lowest income quintile and gradually decrease to about 50 percent for respondents in the top income quintile. In the Netherlands, this gradient is much weaker and minimum replacement rates decrease from 70 percent for the first quintile to 60 percent for the fifth income quintile. Third, we elicit the parameter of relative risk aversion within a retirement preparation context. Our results show that risk aversion is much higher in the Netherlands than in the U.S. The median coefficient of relative risk aversion amounts to 4 for the U.S. and to 7 for the Netherlands. Our data 
also emphasize that researchers need to take a high degree of individual heterogeneity with respect to the risk aversion parameter into account.

A related study that has made use of the Dutch CP in order to examine adequate pension design is van Rooij et al. (2007b). This study investigates whether respondents prefer a mandatory pension system over a privatized one with a free choice of contribution rates and asset allocation strategies. Furthermore, it explores whether respondents show a preference for a defined benefit system with income guarantees over a defined contribution system. The main difference to our study is that we examine various aspects of individual preferences over standards of living rather than preferences over features of pension design.

Seminal survey studies of preference elicitation in the domain of intertemporal choice and choice under risk are Barsky et al. (1997), Donkers et al. (2001), Kapteyn and Teppa (2003), and Kimball et al. (2006). Our analysis also differs from these studies in various respects. First, our corresponding survey questions are more specific in that we concentrate only on intertemporal and risk preferences as far as they relate to retirement preparation. Second, our questionnaire is individually tailored to each respondent's personal financial situation. Third, we present results for two different countries. Given the stark difference in pension institutions between those countries, our comparison allows for judging our results' robustness across different institutional settings.

The rest of the paper is organized as follows. Section 2 provides information about our samples. Section 3 presents our results on ex-ante adequate old age spending in the absence of risk. Section 4 brings risk into play. Section 5 concludes.

\section{The Data}

The Dutch CentERpanel. The Dutch CentERpanel (CP) is hosted by the data collection agency CentERdata at Tilburg University, and the data used for the presented analysis is publicly available from CentERdata. The CP consists of a total of about 
2000 members who regularly fill out internet-based questionnaires, typically on weekends. There are two types of questionnaires. First, panel members are regularly asked about socioeconomic characteristics of their household within the framework of the so-called DNB Household Survey. We use this information to tailor our questions to the respondent's personal financial situation. Second, panel members are invited to answer special-topic questionnaire modules such as ours from time to time.

An outstanding feature of the $\mathrm{CP}$ is that it is representative for the overall Dutch population. Since internet penetration may be systematically lower in some subgroups of the population, CentERdata provides households that do not own a computer or internet connection with an add-on device that allows them to access internet via television. It also provides a television if necessary.

Our questionnaire was conducted on the weekend of March 24/25, 2007, and was again presented one weekend later to those who did not respond on the previous weekend. We presented the survey to panel members who were older than 25 and who were either the household's main breadwinner or his or her spouse. We also included retired panel members, though some questions were deliberately only asked to non-retired respondents. Based on these selection criteria, 835 panel members answered our questionnaire. The actual number of responses per question varies between 550 and 835 .

The American Life Panel. The American Life Panel (ALP) at the RAND institution was modeled after the CP, and grants public access to the data used in this paper. As in the case of the CP, ALP members regularly answer questions on general socioeconomic characteristics. The main difference between the ALP and the CP is that the former is not fully representative of the overall U.S. population. Second, ALP members are not limited to answering a particular questionnaire during a particular weekend, but typically may do so during an entire month.

In the case of the ALP, our questionnaire was fielded in November 2007. Using selection criteria similar to those for the CP, 847 panel members answered our questionnaire. The 
actual number of responses per question varies between about 600 and 847 .

Table 1 shows descriptive statistics for our two samples. The income variable refers to total household income after taxes. Our measure of gross total wealth includes housing wealth, but it excludes (financial) retirement savings. In all our analyses, wealth data enter in the form of wealth quintile dummies. The respondents' highest degree of professional education is indicated by the two dummy variables "no vocational training" and "university degree". The excluded category is the middle one, i.e. if both dummy variables are zero, the corresponding respondent's highest professional degree is a vocational degree. The variable "children at home" indicates whether any children are living at the respondent's home. The figures in Table 1 show that ALP respondents are richer, wealthier and better educated than the average American.

\section{Adequate Old Age Spending in the Absence of Risk}

We address the question of what represents an adequate standard of living during retirement from an ex-ante anticipatory perspective. This is the perspective that corresponds to a preference-based approach which basically underlies all of standard economic theory. From the ex-ante perspective, the question of what represents an adequate standard of living during retirement intrinsically relates to two key trade-offs. The first trade-off is between spending during working life and spending during old age. The second trade-off is between a safe but lower level of old age spending, and a more risky level of spending with a higher expected value. The importance of these trade-offs notwithstanding, there may also be a minimum level of retirement spending below which individuals would not want to fall even in exchange for very high levels of working life or expected old age spending 7

This discussion highlights the three main topics of our questionnaire, namely the in-

\footnotetext{
${ }^{7}$ This would, for instance, be the case for habit formation or Stone-Geary type preferences over intertemporal consumption flows, as well as for the lexicographic loss aversion framework in Binswanger (2007).
} 
tertemporal trade-off, the risk-return trade-off, and the potential existence of a lower bound on acceptable old age spending levels. We start our discussion with the intertemporal trade-off, since this is the most basic aspect of retirement preparation from an economist's point of view.

In the interest of keeping our questionnaire as transparent and simple as possible, our survey questions on the intertemporal trade-off neglects any form of risk. Furthermore, we do not consider any variation of spending within working life or within retirement. This would lead to rather difficult questions and, as a consequence, would reduce the reliability of respondents' answers. Hence, we concentrate on how average spending levels during retirement compare to average spending levels during working life.

Specifically, we present each respondent $i$ a total number of six options of monthly working-life and retirement spending levels $\left(c_{w, i}^{k}, c_{r, i}^{k}\right), k=1,2, \ldots, 6$. The consumption levels $c_{w, i}^{k}, c_{r, i}^{k}$ represent absolute amounts. Respondents are asked to indicate which option they like most. The defining property of each option is the ratio $c_{r, i}^{k} / c_{w, i}^{k}$, which we set at $50,64,76,88,100$, and 140 percent for $k=1,2, \ldots, 6$, respectively. This includes the range of spending ratios that are commonly viewed as potentially adequate. All six options are characterized by an identical present value of lifetime consumption, according to a stylized calculation outlined below.

It is important to stress that we show respondents absolute amounts of money, not percentages. We do so since respondents may find imagining exactly what these percentage numbers would mean for their personal situation difficult. We do not inform respondents that the ratios $c_{r, i}^{k} / c_{w, i}^{k}$ correspond to the particular percentage numbers mentioned above.

The calculation used for determining the present value of total lifetime income and consumption is not intended to be realistic per se. Rather, we want respondents to perceive the options $\left(c_{w, i}^{k}, c_{r, i}^{k}\right)$ as feasible in light of their personal financial situations. In particular, our lifetime income calculation is carried out in such a way that the highest value of $c_{w, i}^{k}$ comes close to a respondent's total monthly household income during working 
life.

Specifically, we assume that the respondent's working life starts at the age of 25 . Furthermore, we assume respondents retire at age 65 in case of the ALP and at 61 in case of the $\mathrm{CP} 8$ We neglect mortality risk and assume that death occurs with certainty after age 85.9

The present value of consumption over the entire life is then given by

$$
\sum_{t=25}^{R-1}\left(\frac{1}{1+r}\right)^{t-25} 12 c_{w, i}^{k}+\sum_{t=R}^{85}\left(\frac{1}{1+r}\right)^{t-25} 12 c_{r, i}^{k}=P V Y_{i}
$$

$R$ denotes the retirement age and amounts to either 65 or $61 . r$ denotes the real risk-free interest rate. (Respondents are first asked to choose their favorite spending profile for an interest rate of one percent and then for an interest rate of six percent.) $P V Y_{i}$ denotes a hypothetical present value of lifetime income for respondent $i$. It is determined according to

$$
P V Y_{i}=\sum_{t=25}^{R-1}\left(\frac{1}{1+r}\right)^{t-25} Y_{i}+\sum_{t=R}^{85}\left(\frac{1}{1+r}\right)^{t-25} 0.64 Y_{i} .
$$

$Y_{i}$ represents respondent $i$ 's total annual household income after taxes, as we observe it before conducting our survey module 10

Our calculation of $P V Y_{i}$ implicitly assumes that retirement income equals 64 percent of working-life income. This allows us to make the options appear realistic to respondents. This can be seen as follows. Suppose that $c_{r, i}^{k} / c_{w, i}^{k}<.64$. In this case, our assumptions would imply that $c_{w, i}^{k}>Y_{i} / 12$. Thus, the respondent would have to borrow, hypothet-

\footnotetext{
${ }^{8}$ In the U.S., Social Security benefits can be claimed beginning at age 62 . The normal retirement age varies between 65 and 67 depending on the year of birth. In the Netherlands, first-pillar benefits can be claimed from the age of 60 on, while the normal retirement age is 65. Effective retirement ages are 64 and 61 for the U.S. and the Netherlands, respectively (OECD, 2006).

${ }^{9}$ According to the 2008 OASDI Trustees Report (OASDI, 2008), life expectancy at age 65 currently amounts to 81.7 for men and 84.2 for women. It is expected to increase to 84.3 for men and to 86.4 for women in 2050.

${ }^{10}$ For retired respondents we set $Y_{i}$ to total annual household income after taxes divided by 0.85 , in order to take the fact that their pre-retirement income was likely to be higher than their current income into account.
} 
ically, if she were to "realize" this option. In contrast, if $c_{r, i}^{k} / c_{w, i}^{k} \geq .64$, then we have $c_{w, i}^{k} \leq Y_{i} / 12$. In particular, for a ratio of 64 percent we approximately have $c_{w, i}^{k}=Y_{i} / 12$, up to rounding. Thus, our assumptions about $P V Y_{i}$ imply that none of the values for $c_{w, i}^{k}$ exceed respondents' monthly income except when $c_{r, i}^{k} / c_{w, i}^{k}=.5$.

Our question on spending profiles was split up into two steps/screens. On a first screen, respondents only saw four options corresponding to spending ratios of $64,76,88$, and 100 percent, respectively. This was meant to avoid respondents having to process an excessive amount of information on one screen. Thus, all options on the first screen exclude hypothetical borrowing. In this way, we avoid alienating respondents with numbers which may appear infeasible to them. Given the avoidance of hypothetical borrowing, the numbers for $c_{w, i}^{k}$ come as close as possible to respondents' monthly income. Only if a respondent chooses a ratio of 64 or 100 percent do we ask on a follow-up screen if he or she would actually prefer the chosen option to that associated with a ratio of 50 or 140 percent, respectively 11

In order to facilitate information processing, all values of $\left(c_{w, i}^{k}, c_{r, i}^{k}\right)$ are rounded to entire multiples of 50 or 20 units of the corresponding currency, depending on the magnitude of $Y_{i}$. (Remember that we show respondents absolute values, not percentages.) The introductory text to our spending profile questions is as follows:

Below you find four options of how you could spend your money over your lifetime. For each option the first column indicates how much your household could spend on average per month from age 25 until retirement. Thus, this refers to your total (working) age from age 25 until retirement, not just the remaining (working) age. The second column indicates how much your household could spend during retirement. Please think of all your expenditures, such as food, clothing, accommodation, insurance, traveling etc. Assume that the

\footnotetext{
${ }^{11}$ We could have chosen a "replacement rate" of 50 instead of 64 percent in our calculation of $P V Y_{i}$. However, this would have pushed the values of $c_{w, i}^{k}$ for all but the 50 percent option quite far away from $Y_{i} / 12$.
} 
numbers below show what you can spend after having already paid for taxes. Assume also that prices of the things you spend your money on remain the same in the future as today (no inflation). If you had a choice, which option would you like most?12

Table 2 shows an example of a table with the actual options appearing below the above text. In the case of Table 2, the numbers correspond to a monthly household income after taxes of 3,000 U.S. dollars. Table 2 refers to an interest rate of one percent. After having indicated their favorite profile, respondents are presented with a second table, corresponding to an interest rate of six percent. In this table, the ratios of the spending levels are identical. However, for a higher interest rate, achieving a given level of retirement spending requires giving up less working-life spending. As a result, the distances between the numbers in the first column are smaller and the distances in the second column are larger.

It is important to stress that a respondent choosing her most-preferred profile $\left(c_{w, i}^{k}, c_{r, i}^{k}\right)$ from Table 2 need not have an understanding of compound interest rate calculations, inflation or any other technical detail. Respondents only need a well-defined preference ordering over the different spending profiles. The fact that individuals have such a preference ordering is probably the key assumption in economics and we adopt this assumption for our analysis here 13

The results are shown in Table 3. The key observations are the following. First, irrespective of the sample and the level of the interest rate, only very few respondents preferred a spending profile corresponding to a ratio of 50 or 64 percent. Second, there is substantial mass concentrated on the options corresponding to spending ratios of 76,88 ,

\footnotetext{
${ }^{12}$ For single households and respondents that are already retired the text is adapted accordingly.

${ }^{13}$ This assumption is, of course, very different from the assumption that individuals would be able to implement their most preferred spending profile. Behavioral economists have identified several reasons why individuals may be unable to implement the choices that are in their best self-interest. These include financial illiteracy (Lusardi and Mitchell, 2007; van Rooij et al., 2007a) and procrastination (see Beshears et al., 2008).
} 
and 100 percent. Third, the 140 percent option is very popular in the U.S., but not in the Netherlands, at an interest rate of one percent. Finally, consistent with basic economic theory, the 140 percent option is much more popular for an interest rate of six percent than for an interest rate of one percent in both countries.

The differences in the distributions of preferred spending ratios between the two samples are statistically significant 14 This mainly reflects the fact that the 140 percent option is much more popular in the U.S. Two explanations may be put forward for this fact. First, U.S. respondents may expect to face higher out-of-pocket costs for medical treatments and nursing homes (see footnote21 below). Second, Americans may find postponing consumption until retirement as a complement to leisure more desirable. This is consistent with the fact that the number of vacation days is typically much lower in the U.S. than in the Netherlands. 15 As a result, people working in the U.S. may find delaying spending power until retirement - when they have the time to enjoy leisure - preferable.

Based on our data, we have no means for investigating the second explanation. However, our survey allows us to shed some light on the first one. If respondents who choose an increasing spending profile did so in anticipation of high out-of-pocket medical costs, we should also expect these respondents to indicate a particularly high level of old age spending below which they may not want to fall at all costs. Since our survey also contains a question on such a minimum acceptable level of old age spending (see Section 4.1), we can test this hypothesis. We do not find that respondents that choose a spending ratio of 140 percent indicate a systematically higher level of a minimally acceptable old age spending level. Thus, the choice of a spending ratio of 140 percent may reflect a preference for an increasing spending profile rather than exposure to a high amount of risk.

A very interesting question is whether the choice of a particular spending profile sys-

\footnotetext{
${ }^{14}$ Based on a Kolmogorov-Smirnov test, equality is rejected at the 1-percent significance level.

${ }^{15}$ In 2005 , the number of annual hours worked per worker amounted to about 1,900 in the U.S. and about 1,400 in the Netherlands (OECD, 2008).
} 
tematically relates to respondents' socioeconomic characteristics. We explore this by regressing the spending ratio corresponding to the chosen spending profile on a range of explanatory variables including the respondent's income and wealth quintiles, an age polynomial, as well as all other general household characteristics shown in Table 1. In the case of the ALP, no single variable is significantly related to the chosen spending profile. Specifically, we find that a variable indicating people's retirement status has neither an economically nor a statistically significant effect, indicating that choices do not differ between those who are retired and those who are not retired. In the case of the $\mathrm{CP}$, households that have children as well as those with a university degree are found to prefer a marginally lower spending ratio 16 All these findings are very robust across many different specifications of OLS and ordered probit regressions. We therefore conclude that the heterogeneity of respondents' answers reflects, to a major extent, pure preference heterogeneity, not heterogeneity with respect to socioeconomic characteristics.

One concern with our questions on preferred spending profiles may be whether respondents really understand that the spending levels associated with working life refer to the entire working life, not just to their remaining working life. If not, then older respondents may find it desirable to choose a profile with a high spending ratio. This would then imply that age is significantly related to respondents' choices. Regardless of the order of the age polynomial, the included age variables are neither jointly nor individually significant in any of our regressions. This leads us to the conclusion that respondents clearly were able to understand our questions.

In order to explore whether respondents indicate choices that relate to their true preferences, we randomized the order of the response options. Respondents were randomly assigned to one of two treatments. Half of the respondents saw the numbers arranged in the order as in Table 2, where the order of the spending ratios is decreasing. The other

\footnotetext{
${ }^{16}$ Results are available upon request. In case of the $\mathrm{CP}$, households with children living at home or with a university degree choose a spending ratio that is about five percent lower, everything else being equal.
} 
half saw the numbers arranged with an increasing order of spending ratios. In order to investigate the effects of these randomization treatments, we include a dummy variable indicating the order in which the response options are arranged in all regressions for preferred spending ratios discussed above. The resulting coefficients of the randomization dummy are always insignificant and very small. Furthermore, the inclusion of the dummy does not change the coefficients of the other included variables. As an additional formal test of the answer quality, we estimate models that are fully interacted with the randomization dummy. The corresponding F-tests for the joint significance of all interaction terms are insignificant for both the CP and the ALP.

To further explore the quality of the respondents' answers, we make use of three variables which we treat as measures of the degree to which respondents provide "informed" answers. At the end of our questionnaire we ask respondents to indicate whether or not they agree with the following statements 17

1. Many questions didn't make sense to me.

2. Many questions were too abstract for me.

3. I find it very difficult to imagine how much money I would want to have during retirement.

Respondents may check either of the options (1) fully disagree, (2) somewhat disagree, (3) somewhat agree, (4) fully agree. The percentage of respondents who either fully or somewhat disagree amounts to 71, 62, and 75 percent for the three statements, respectively, for the ALP. For the CP the corresponding numbers are 58, 45, and 18 percent, respectively 18 We use the answers to the above question to group respondents into an

\footnotetext{
${ }^{17}$ It has been observed that respondents sometimes show a tendency to agree when asked to rate a particular statement (Clark and Schober, 1992). To set bars high, we therefore ask respondents whether our questions did not make sense to them. Moreover, we also randomized the ordering of the four answer categories of these questions, and we did not find any significant impact on response behavior based on the corresponding Kolmogorov-Smirnov tests for distributional differences.

${ }^{18}$ The reason that most likely explains why ALP respondents have a clearer idea of the standard of
} 
"informed" and a "less informed" subgroup. As before, whatever tests we run, we find that being a member of the informed group never affects response behavior in any significant way, i.e. the coefficients on dummy variables indicating informed respondents are insignificant in all regressions that we consider 19 We view this as an indication that even respondents who feel somewhat less at ease with our questions provide us with meaningful answers.

Overall, we draw two main conclusions from the results discussed in this section. First, individual preferences are fairly heterogeneous. Second, in spite of this, most respondents agree that spending profiles that correspond to ratios below 70 percent do not seem desirable. This applies to both the Netherlands and the U.S. We thus infer from this that adequate spending ratios should exceed at least 70 percent. In the case that old age spending is exposed to risk, this would mean that the certainty equivalence value of old age spending should exceed at least 70 percent of working-life spending.

\section{Bringing Risk into Play}

We consider risk from two different perspectives. First, we conceptualize risk from the perspective of a lower limit on old age spending below which an individual would not want to fall below in almost any case. This represents a particularly simple framework for thinking about risk since it does not require evaluating any risk-return trade-off. Such a framework corresponds to the logic of poverty thresholds as well as to preferences with habit formation or Stone-Geary utility functions 20 Information on such a minimum acceptable level of old age spending is very useful for thinking about adequate retirement preparation. It specifies a benchmark spending level that an individual may want to ex-

living during retirement that they envisage is that institutions in the U.S. require individuals to take much more own responsibility for their retirement preparation. This may induce people to think more carefully about their retirement needs. In the Netherlands, a typical worker belongs to a mandatory defined benefit scheme that typically offers an after-tax replacement rate of above 80 percent.

${ }^{19}$ Results are available upon request.

${ }^{20}$ See Binswanger (2007). 
ceed, from an ex-ante point of view, with a very high probability. Thus, such a benchmark helps to identify adequate asset allocation strategies for individual retirement accounts. It also implies an overall lower bound on adequate savings for retirement.

Second, we are interested in how respondents evaluate potential risk-return trade-offs. We therefore also include a standard set of questions for identifying coefficients of relative risk aversion. The innovation here is that we elicit this parameter strictly in the context of retirement preparation and that the options respondents may choose between are again tailored to their personal financial situation.

This section starts with the analysis of lower bounds on old age spending.

\subsection{Lower Limits on Adequate Old Age Spending}

We present respondents the following question.

This question refers to the overall level of spending that applies to you and your partner during retirement. What is a minimal level of monthly spending that you never want to fall below during retirement, at all costs? Please think of all your expenditures, such as food, clothing, accommodation, insurance etc. Assume that prices of the things you spend your money on remain the same in the future as today (no inflation).

The question is framed in a way that we should expect answers to differ across different countries if they are characterized by different institutions. For instance, the answers to this question may differ between countries with different health insurance schemes.21

\footnotetext{
${ }^{21}$ In contrast to the U.S., health insurance is compulsory for everyone in the Netherlands and pays for most doctor visits and pharmaceuticals as well as for hospital stays up to one year. Furthermore, every resident is covered by a public long-term care insurance scheme (dubbed AWBZ) that covers nursing homes and long-term hospital stays. The U.S. Medicare system requires a 20 percent copayment for hospital stays, a feature that has no counterpart in the Netherlands. Covering this copayment requires an extra (non-mandatory) so-called Medigap insurance. (The requirement of a copayment drops if Medicaid covers care costs.)
} 
For the ALP, the 25th, 50th and 75th percentile of the answers amount to 2,000, 3,000, and 4,000 year-2007 U.S. dollars per month, respectively. The 25th, 50th and 75 th percentiles of the ratio of the answers to total monthly household income after taxes amount to $.48, .73$, and .95 , respectively. For the CP, the respective absolute numbers are $1,200,1,600$, and 2,000 year-2007 euros per month. The respective ratios of the answers to total household income after taxes are $.56, .72$, and .88 .

Table 4 shows median regressions with the answers to the above question as the dependent variable 22 Our estimation results show that income primarily determines the minimally acceptable spending level 23 In particular, minimum spending levels neither depend in a statistically significant way on age, regardless of the order of the age polynomial, nor on whether children live at home. This latter result means that neither the current family situation nor the current age systematically affects the way respondents anticipate their retirement needs. This is exactly what we should expect if respondents rationally anticipate their retirement needs. We view the fact that we actually do observe this pattern as an indication of the quality of our responses.

Interestingly, retired respondents are significantly more conservative with respect to their minimum needs in the Netherlands. In contrast, respondents with a university degree are less conservative. It is noteworthy that the regression results in Table 4 are highly robust across many different specifications that we have estimated 24

The regression results in Table 4 allow for calibrating minimum acceptable spending levels for any combination of household characteristics we may be interested in. Since our results show income to be clearly the most important determinant for minimum spending levels, we calibrate such spending levels for each income quintile. We do so for a non-

\footnotetext{
${ }^{22}$ Given the skewness of the data, we prefer median regressions to OLS, since a median regression imposes less restrictive assumptions and therefore is a more robust estimation method.

${ }^{23}$ For the ALP, the dummy variables indicating income quintiles do not refer to the quintiles according to our sample but according to the Current Population Survey. Since the ALP is not representative for the U.S. population, this makes it easier to interpret the results. For the CP, the quintiles refer to our sample.

${ }^{24}$ These are available upon request.
} 
single household aged 60 that is not retired 25 Furthermore, we set the values of the dummy variables for children, home ownership, no vocational training, and for having a university degree to zero. Concerning wealth, we assign to each income quintile that particular wealth quintile to which the median member of a particular income quintile belongs to.

The results for these calibrations are shown in Table 5. The upper panel refers to the ALP and the measurement units are year-2007 U.S. dollars. The lower panel refers to the CP and the units are year-2007 euros. The first column in each of the two panels in Table 5 shows the calibrated monthly minimum spending levels. The second column simply reports the monthly median after-tax incomes in our samples for each income quintile. The striking pattern in Table 5 is that the increments in minimum spending levels are smaller than the increments in income. This pattern is particularly pronounced for the U.S., which is reflected in the decreasing ratios of spending levels to incomes, as shown in the third column of Table 5. In the U.S., the minimum spending-to-income ratio is even slightly higher than one for the first quintile. This suggests that households in our first quintile have serious problems making ends meet. This is substantiated by the fact that the median monthly income of households in our first income quintile (see Table 5) is already far below the poverty threshold in the U.S. which is 1,129 U.S. dollars per month for two-person households and 1,378 U.S. dollars for three-person households 26

For all other quintiles in case of the U.S., and for all quintiles in the Netherlands, the calibrated replacement rates are below one. This suggests that people anticipate that they would be able to cut back if necessary. This result is consistent with the recent finding of Aguiar and Hurst (2007) that the elderly spend less money for a given amount of "consumption intake".

\footnotetext{
${ }^{25}$ Almost identical results are obtained for ages of 40 or 50 .

${ }^{26}$ These poverty thresholds refer to the year 2007 and are provided by the U.S. Census Bureau, see: http://www.census.gov/hhes/www/poverty/threshld/thresh07.html.
} 
What do we further learn from Table 55? Our calibrations are useful in two further respects. First, they prove helpful in designing adequate asset allocation strategies. Any asset allocation strategy maps into a distribution of available resources during retirement. Our calibrations help identify adequate portfolio strategies in that, say, the 90th percentile of the resulting distribution of monthly spending should exceed the values in the first column of Table 5. Second, the numbers in Table 5 may be useful for thinking about adequate benefit levels in a mandatory pension system. If society believes that pension systems should be mandatory since individuals may not have enough information or selfcontrol in the domain of retirement preparation, then the numbers in the first column of Table 5 may provide useful benchmarks for income-specific benefit levels provided by a mandatory system.

Clearly, adequate old age spending levels depend on institutional settings within a particular country. In this sense, our results are only suggestive for countries other than the U.S. and the Netherlands. The discussion in this section provides guidelines on how other countries may proceed in order to learn about citizens' perceptions of minimally adequate old age spending levels when conducting surveys of their own.

As in the case of spending profiles discussed in the last section, we conclude this section with the investigation of whether we can judge respondents' answers as informed and reliable. As described in Section 3, we therefore classify respondents into an informed and a less informed subgroup. Once again, we find no significant difference in response behavior between either subgroup. This holds for all three information measures. In particular, if dummy variables indicating the less informed subgroup are added as explanatory variables in the regressions discussed in this section, e.g. the regressions reported in Table 4. they are never significant and they do not have any effect on the coefficients of the remaining explanatory variables. 


\subsection{Relative Risk Aversion}

Our final question elicits the coefficient of relative risk aversion. We employ the widelyused multiple price list design of Holt and Laury (2002). Specifically, respondents are presented with the following question.

In the following table we present five choices to you. You can always choose between two different types of income during retirement, income of type $A$ and of type B. Please assume that these incomes include all sources of money available to you during retirement. In particular, there is no additional money available from spending down your wealth. If you choose income type A, the total income during retirement for you and your partner will always be $\left[Z_{i}^{s}\right]$ per month, independent of the performance of the economy. If you choose type $B$, the total income during retirement for you and your partner depends on the performance of the economy (e.g. on returns in financial markets). If the economic performance is unfavorable it will be $\left[Z_{i}^{r l}\right]$ per month. If the performance is favorable it will be $\left[Z_{i}^{r h}\right]$ per month. The five choices differ only in terms of the chance that the favorable or unfavorable economic performance will materialize. Which income type would you choose?

A: $\left[Z_{i}^{s}\right]$ Euros, or

$B:[1-\pi]$ percent chance of $\left[Z_{i}^{r l}\right]$, and $[\pi]$ percent chance of $\left[Z_{i}^{r h}\right]$. $(\ldots)$

The probability $\pi$ is set to $50,60,70,80$, and 90 percent for the five choice situations, respectively. We set $Z_{i}^{s}$ to 85 percent of a respondent's current monthly income, $Z_{i}^{r l}$ to 70 and $Z_{i}^{\text {rh }}$ to 100 percent of her current monthly income. However, it is important to stress that, as in the case of risk-free spending ratios in Section 3 , respondents see absolute money values and are not made aware that these values correspond to particular replacement rates. All values are again rounded to entire multiples of 50 or 20 units of 
the corresponding currency, depending on their magnitude.

Under CRRA preferences, expected utility of a random prospect $\tilde{x}$ is defined as

$$
U(\tilde{x})=E\left[\frac{1}{1-\theta} \tilde{x}^{1-\theta}\right]
$$

where $\theta$ denotes the parameter of relative risk aversion and $E$ the mathematical expectation operator. We identify the value of $\theta$ for each respondent by using information on her switching point. Specifically, respondents indicate whether they would prefer the safe option (A) or the risky option (B) when the probability for the high realization associated with the risky option amounts to 50,60, 70, 80, or 90 percent, respectively. If, for instance, a respondent prefers the safe option in the case of 60 percent and the risky option in case of 70 percent, his switch point is given by the 70-percent prospect. We then know that $1 /(1-\theta)\left(Z_{i}^{s}\right)^{1-\theta} \geq 0.4 /(1-\theta)\left(Z_{i}^{r l}\right)^{1-\theta}+0.6 /(1-\theta)\left(Z_{i}^{r h}\right)^{1-\theta}$ but $1 /(1-\theta)\left(Z_{i}^{s}\right)^{1-\theta} \leq 0.3 /(1-\theta)\left(Z_{i}^{r l}\right)^{1-\theta}+0.7 /(1-\theta)\left(Z_{i}^{r h}\right)^{1-\theta}$. This allows us to identify the highest value of $\theta$ that is consistent with the respondent's switching point 27

For the ALP, the 25th, 50th and 75th percentiles of the observed distribution of $\theta$ are 2, 4 and 7, respectively. For the $\mathrm{CP}$ they amount to 4, 7, and 12. Figures 1 and 2 show estimated kernel densities for both samples.28 Clearly, the Dutch respondents are far more risk averse than the U.S. respondents. However, Figures 1 and 2 show that there is also considerable heterogeneity within each country. This is an important result for calibration studies aiming to identify optimal retirement saving and asset allocation strategies as well as an optimal design of a mandatory pension system. It indicates the importance of taking individual preference heterogeneity into account.

\footnotetext{
${ }^{27}$ Identical with Holt and Laury (2002), we use the (last) point where a subject switches from option A to option B. The vast majority of our respondents (95 percent for the CP, and 94 percent for the ALP) only switches once. As in Holt and Laury (2002), we find that the analysis reported here does not change if we drop respondents who switch from B back to A.

${ }^{28}$ An Epanechnikov kernel and Silverman's rule of thumb (Silverman, 1986) for bandwidth selection have been used for the kernel density estimation.
} 
We are also interested in the question whether socioeconomic background characteristics are systematically related to respondents' risk aversion. We do not identify any systematic relationship, neither in the ALP nor in the CP 29 The fact that CP respondents are substantially more risk averse than ALP respondents may have several explanations. First, it may reflect that the ALP is less representative for the general population than the CP. Second, institutions may be such that they are more likely to favor risk-taking in the U.S. Third, the effect may be cultural. Since ALP respondents are wealthier and better educated than the average American, the first explanation would require that income, wealth, or education be positively associated with measured relative risk aversion. However, we do not find any such statistically significant associations. The second explanation would entail the U.S. social insurance system covering more risks than its Dutch counterpart. This is clearly not the case. This renders the third explanation the most likely one.

As before, we also investigate response quality. First, the order of the response options was randomized. If we regress $\theta$ on the usual socioeconomic variables (see Table 1 ) and include a dummy that indicates the randomization treatment, this dummy is always insignificant and its inclusion does not change the coefficients of the other regressors. This result holds for other specifications, e.g. specifications with only subsets of the socioeconomic variables. We also estimate models where the randomization dummy is fully interacted with all other explanatory variables. Further underlining our observation that the order of response options does not play a role, an F-test on joint significance of all interaction terms is insignificant for the ALP. The F-test is significant for the CP, but the significance vanishes as soon as we stratify the sample by retirement status. Second, we investigate whether the degree to which respondents feel informed (which we elicited based on three questions asked at the end of the survey, see Section 3) systematically affects respondent's answers. Fully in line with all our previously reported results, we

\footnotetext{
${ }^{29}$ Regression results, again containing all variables presented in Table 1, are available upon request.
} 
do not find any such evidence. Dummies indicating informed respondents are always insignificant and their inclusion does not affect the coefficients of the other regressors.

\section{Conclusion}

In this paper we use a specifically designed internet survey conducted in the U.S. and the Netherlands to address the question of what represents an adequate standard of living during old age. We address this question from an ex-ante point of view, consistent with the perspective suggested by economic theory. A series of randomization treatments as well as various feedback questions show that there is little reason to doubt that respondents' answers to our questionnaire are highly meaningful. Our findings further indicate that respondents are able to look beyond their current household situation when answering our questions about an adequate standard of living during retirement. Overall, people seem to have a fairly good idea of the level of old age spending that they find desirable.

We find that individuals aim to achieve a spending profile where, under normal circumstances, old age spending exceeds 70 percent of average working-life spending in both countries. Bringing risk into play, there is clear evidence that individuals do not want to fall below a certain lower limit of old age spending. We use respondents' answers to calibrate minimum income replacement rates for each income quintile. For the U.S. sample, these range between 100 percent for the lowest quintile and 50 percent for the highest. For the Netherlands, the corresponding numbers are 70 and 60 percent, respectively. Turning to the question how respondents evaluate risk-return trade-offs, we find considerable heterogeneity within and between samples. For the U.S. sample, the 25th and 75th percentile of the distribution for the coefficient of relative risk aversion amount to 2 , and 7 , respectively. For the Dutch sample, they amount to 4 and 12, respectively.

Our results are useful in three respects. First, they help identify a benchmark of adequate old age spending levels. In this respect, we view our results about minimally 
acceptable spending levels as particularly helpful. They can be used directly to infer critical lower bounds on wealth accumulation. Second, our results can be used to offer advice to uninformed individuals. Third, we may infer optimal contribution and benefit levels for a mandatory pension system. Allowing individuals to achieve the minimally acceptable spending levels identified in this paper would be a natural way of determining benefit levels. Binswanger (2007) provides a simple framework that may prove useful for analyzing how to achieve this by combining a funded with a pay-as-you-go pension component.

In future research, our approach using an individually tailored and randomized survey design for eliciting information on preferences can be applied in various other domains that are important for policy. For example, consider information on individual preferences with respect to the trade-off between lower contributions to the welfare state and higher levels of risk borne by private individuals. Such information is relevant for the identification of a desirable design of social policy as well as of desirable macroeconomic policies. Carefully elicited information on people's preferences will stimulate the interaction between theoretical and empirical researchers, will make the policy discourse richer, and may ultimately lead to better policies. 


\section{References}

Aguiar, Mark and Hurst, Erik (2007), "Life-Cycle Prices and Production," American Economic Review, 97(5), 1533-1559.

Barsky, Robert B., Juster, Thomas F., Kimball, Miles S., and Shapiro, Matthew D. (1997), "Preference Parameters and Behavioral Heterogeneity: An Experimental Approach in the Health and Retirement Study", Quarterly Journal of Economics, 112(2), $537-579$

Bernheim, Douglas B. (1992), "Is the Baby Boom Generation Preparing Adequately for Retirement?", Merrill Lynch, New York.

Bernheim, Douglas B., Forni, Lorenzo, Gokhale, Jagadeesh, and Kotlikoff, Laurence J. (2000), "How Much Should Americans Be Saving for Retirement?" American Economic Review, 90(2), Papers and Proceedings, 288-292.

Beshears, John, Choi, James J., Laibson, David, and Madrian, Brigitte C. (2006), "The Importance of Default Options for Retirement Savings Outcomes: Evidence from the United States", NBER Working Paper 12009.

Beshears, John, Choi, James J., Laibson, David, and Madrian, Brigitte C. (2008), "How Are Preferences Revealed?", Journal of Public Economics, 92, 1787-1794.

Binswanger, Johannes (2007), "Risk Management of Pensions from the Perspective of Loss Aversion", Journal of Public Economics, 91, 641-667.

Clark, Herbert H. and Schober, Michael F. (1992), "Asking Questions and Influencing Answers", in: Tanur, Judith M. (ed.), Questions About Questions: Inquiries into the Cognitive Bases of Surveys, Russell Sage Foundation, New York.

Donkers, Bas, Melenberg, Bertrand, and van Soest, Arthur (2001), "Estimating Risk Attitudes Using Lotteries: A Large Sample Approach", Journal of Risk and Uncertainty, $22(2), 165-195$.

Holt, Charles A., and Laury, Susan K. (2002), "Risk Aversion and Incentive Effects", American Economic Review, 92(5), 1644-1655. 
Kapteyn, Arie, and Teppa, Federica (2003), "Hypothetical Intertemporal Consumption Choices", Economic Journal, 113, C140-C152.

Kimball, Miles S., Sahm, Claudia R., and Shapiro, Matthew D. (2006), "Measuring Time Preferences and the Elasticity of Intertemporal Substitution with Web Surveys", Working Paper.

Lusardi, Annamaria, and Mitchell, Olivia S. (2007), "Baby Boomer Retirement Security: The Roles of Planning, Financial Literacy, and Housing Wealth", Journal of Monetary Economics, 54, 205-224.

Munnell, Alicia, Webb, Anthony, and Delorme, Luke (2006), "Retirements at Risk: A New National Retirement Index", Boston College Center for Retirement Research.

OASDI (2008), "The 2008 Annual Report of the Board of Trustees of the Federal Old Age and Survivors' Insurance and Federal Disability Insurance Trust Funds", U.S. Government Printing Office, Washington D.C.

OECD (2006), "Live Longer, Work Longer", OECD, Paris.

OECD (2007), "Pensions at a Glance: Public Policies across OECD Countries", OECD, Paris.

OECD (2008), Economic Policy Reforms: Going for Growth, OECD, Paris.

Poterba, James, Rauh, James, Venti, Steven, and Wise, David (2003), "Utility Evaluation of Risk in Retirement Saving Accounts", NBER Working Paper 9892.

Scholz, John K., Seshadri, Ananth, and Khitatrakun, Surachai (2006), "Are Americans Saving 'Optimally' for Retirement?", Journal of Political Economy, 114(4), 607-643.

Silverman, Bernard W. (1986), Density Estimation for Statistics and Data Analysis, Chapman and Hall, London.

Skinner, Jonathan (2007), "Are You Sure You're Saving Enough for Retirement?", Journal of Economic Perspectives, 21(3), 59-80.

Thaler, Richard H. (1994), "Psychology and Savings Policies", American Economic Review, Papers and Proceedings, 84(2), 186-192. 
Van Rooij, Maarten C.J., Lusardi, Annamaria, and Alessie, Rob (2007a), "Financial Literacy and Stock-Market Participation," NBER Working Paper No. 13565.

Van Rooij, Maarten C.J., Kool, Clemens J.M., and Prast, Henriëtte M. (2007b), "RiskReturn Preferences in the Pension Domain: Are People Able to Choose?", Journal of Public Economics, 91(3-4), 701-722. 
Figure 1: The distribution of relative risk aversion for the U.S.

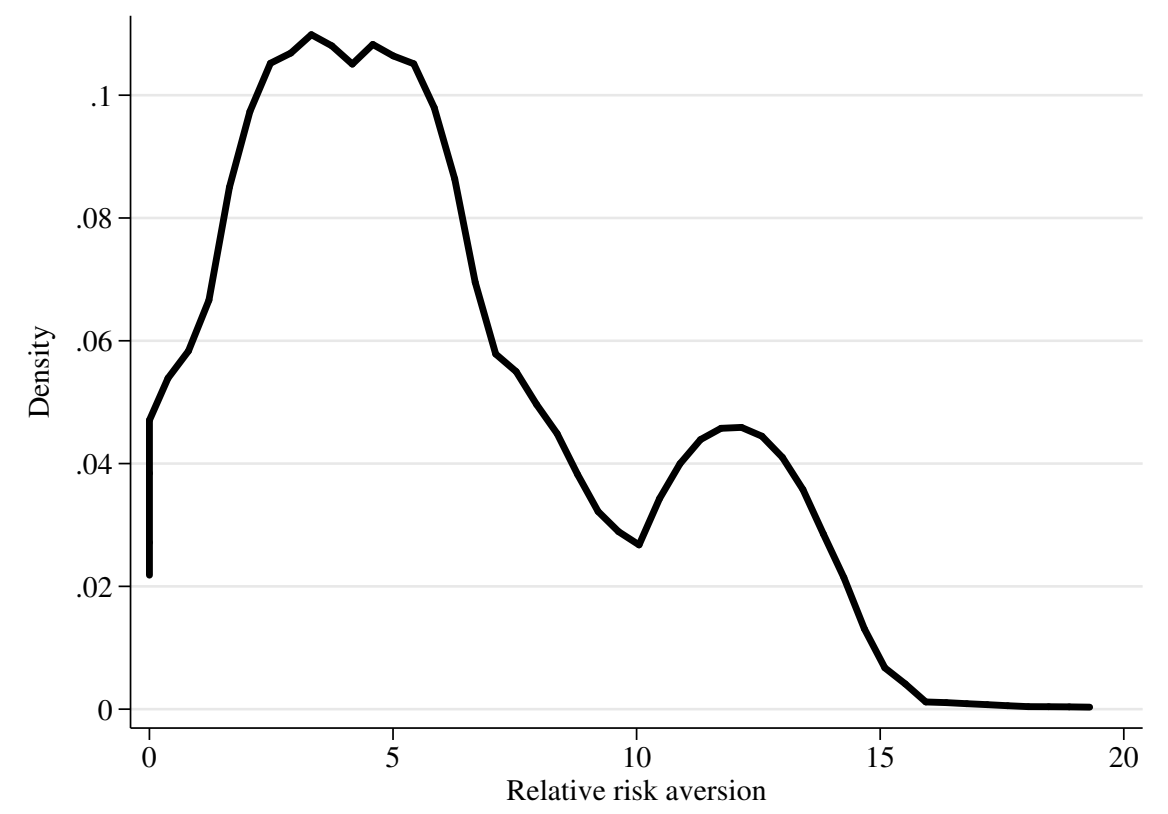

Figure 2: The distribution of relative risk aversion for the Netherlands

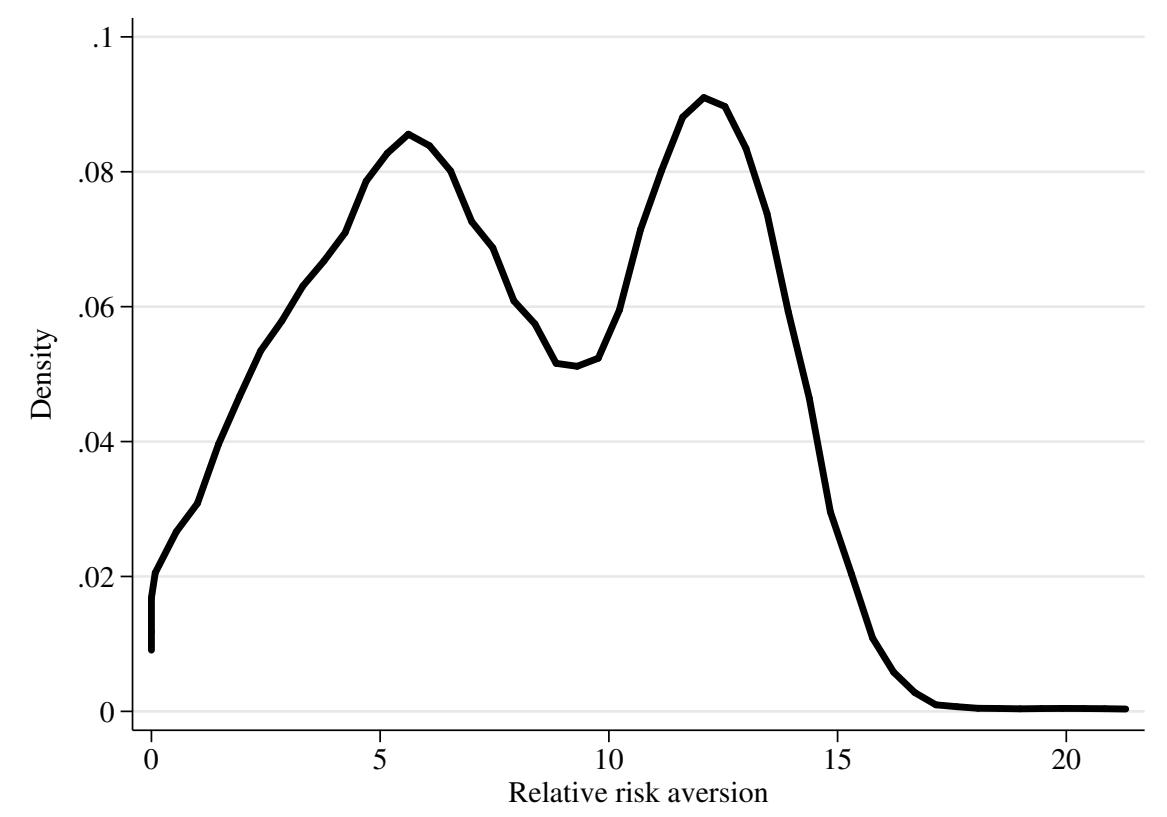


Table 1: Descriptive Statistics

\begin{tabular}{|c|c|c|c|c|c|c|}
\hline & \multicolumn{3}{|c|}{ 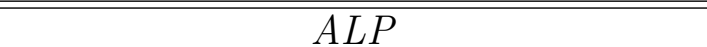 } & \multicolumn{3}{|c|}{ 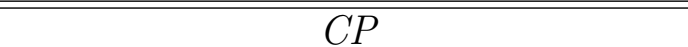 } \\
\hline & Mean & Median & Standard deviation & Mean & Median & Standard deviation \\
\hline Age & 51.04 & 52 & 14.29 & 50.40 & 51 & 16.10 \\
\hline Income & 5,000 & 4,521 & 6,001 & 2,419 & 2,250 & 1,612 \\
\hline Total gross wealth & 507,409 & 345,113 & 632,613 & 228,756 & 206,725 & 228,138 \\
\hline Single & 0.21 & 0 & 0.41 & 0.21 & 0 & 0.40 \\
\hline Children at home & 0.25 & 0 & 0.44 & 0.36 & 0 & 0.48 \\
\hline Home ownership & 0.80 & 1 & 0.40 & 0.71 & 1 & 0.45 \\
\hline Retired & 0.27 & 0 & 0.44 & 0.22 & 0 & 0.41 \\
\hline No vocational training & 0.17 & 0 & 0.38 & 0.31 & 0 & 0.46 \\
\hline University degree & 0.47 & 0 & 0.50 & 0.11 & 0 & 0.31 \\
\hline
\end{tabular}

Note: Total number of respondents is 842 for the ALP and 835 for the CP. Income and wealth is measured in year-2007 U.S. dollars for the ALP and in year-2007 euros for the CP. 
Table 2: Options of expenditures profiles (example)

\begin{tabular}{lcc}
\hline \hline & $\begin{array}{c}\text { Monthly spending during working life (age } \\
\text { 25 until retirement) in U.S. dollars }\end{array}$ & $\begin{array}{l}\text { Monthly } \\
\text { retirement in U.S. dollars }\end{array}$ \\
\hline Option A & 2,650 & 2,650 \\
Option B & 2,750 & 2,400 \\
Option C & 2,850 & 2,150 \\
Option D & 2,950 & 1,900 \\
\hline \hline
\end{tabular}

Table 3: Preferred spending ratios

\begin{tabular}{lcccc}
\hline \hline \multirow{2}{*}{ Spending ratio } & \multicolumn{2}{c}{ ALP } & \multicolumn{2}{c}{ CP } \\
& 1 percent & 6 percent & 1 percent & 6 percent \\
\hline 50 percent & 5 & 7 & 4 & 6 \\
64 percent & 11 & 7 & 6 & 4 \\
76 percent & 17 & 14 & 22 & 14 \\
88 percent & 25 & 21 & 36 & 33 \\
100 percent & 18 & 11 & 24 & 23 \\
140 percent & 24 & 39 & 8 & 20 \\
\hline \hline
\end{tabular}

Note: The numbers indicate percentages of observations. Total number of observations are 787 for the ALP and 708 for the CP. 
Table 4: Median regressions for minimally acceptable spending levels

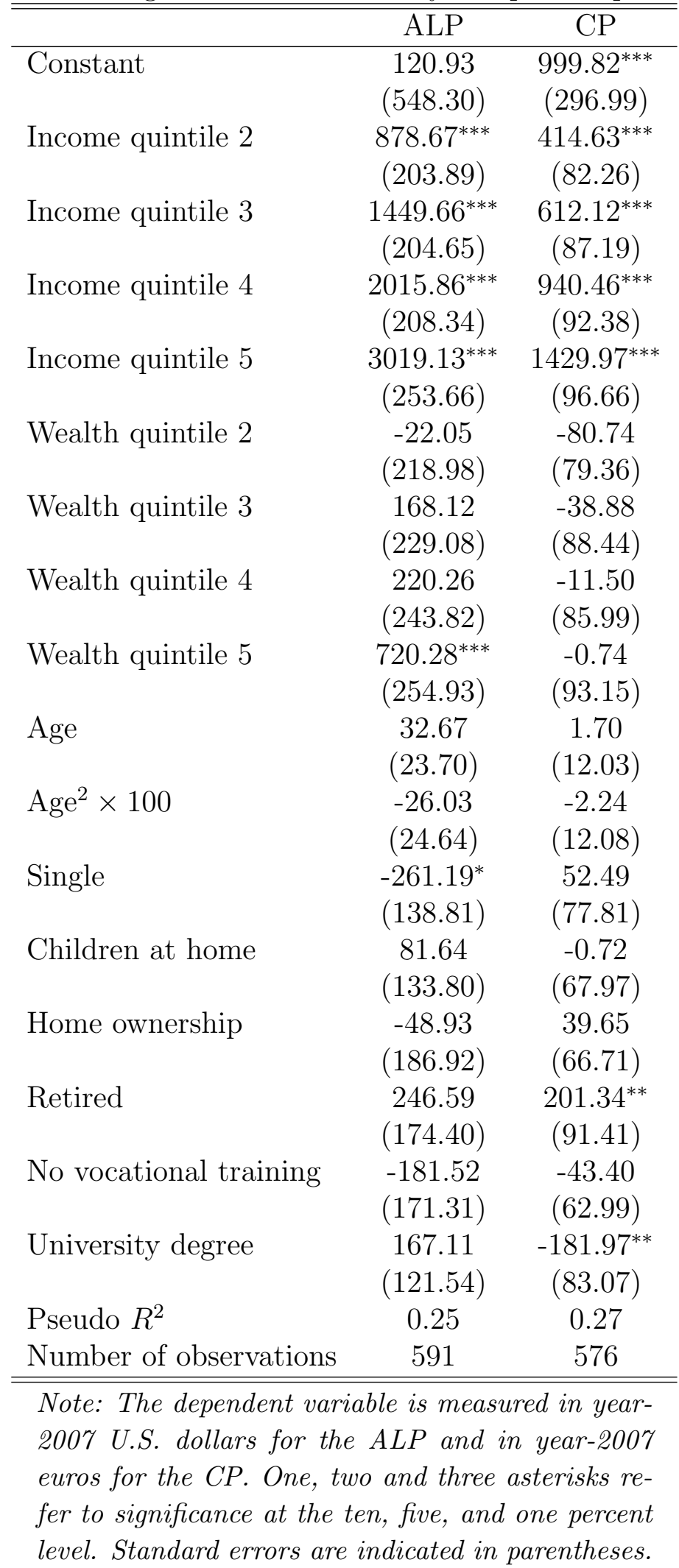


Table 5: Predicted minimally acceptable old age spending levels per month

\begin{tabular}{cccc}
\hline \hline & \multicolumn{3}{c}{ ALP } \\
\cline { 2 - 4 } Quintile 1 & Minimum spending & Median income & Ratio \\
\cline { 2 - 4 } Quintile 2 & 2,144 & 1,058 & 1.08 \\
Quintile 3 & 2,762 & 2,344 & 0.85 \\
Quintile 4 & 3,377 & 3,215 & 0.86 \\
Quintile 5 & 4,884 & 6,384 & 0.53 \\
& \multicolumn{4}{c}{ CP } \\
\cline { 2 - 4 } Quintile 1 & 951 & 9,054 & 0.54 \\
\cline { 2 - 4 } Quintile 2 & 1,327 & 1,359 & 0.69 \\
Quintile 3 & 1,525 & 1,835 & 0.72 \\
Quintile 4 & 1,852 & 2,300 & 0.66 \\
Quintile 5 & 2,370 & 2,875 & 0.64 \\
\hline \hline
\end{tabular}

Note: Minimum spending levels are calculated setting age to 60. In case of the ALP, income quintiles refer to the Current Population Survey, not the ALP itself. Numbers in the upper panel represent year-2007 U.S. dollars. Numbers in the lower panel represent year-2007 euros. 


\section{Discussion Paper Series}

Mannheim Research Institute for the Economics of Aging Universität Mannheim

To order copies, please direct your request to the author of the title in question.

\begin{tabular}{|c|c|c|c|}
\hline Nr. & Autoren & Titel & Jahr \\
\hline $160-08$ & Mathias Sommer & $\begin{array}{l}\text { Imputation and Harmonisation of Income, } \\
\text { Consumption, Savings and Wealth Data from } \\
\text { the German Income and Expenditure Survey }\end{array}$ & 08 \\
\hline $161-08$ & Karsten Hank & Generationenbeziehungen im alternden Europa & 08 \\
\hline $162-08$ & $\begin{array}{l}\text { Axel Börsch-Supan, } \\
\text { Karsten Hank, } \\
\text { Hendrik Jürges, } \\
\text { Mathis Schröder }\end{array}$ & $\begin{array}{l}\text { Longitudinal Data Collection in Continental } \\
\text { Europe: Experiences from the Survey of Health, } \\
\text { Ageing and Retirement in (SHARE) }\end{array}$ & 08 \\
\hline $163-08$ & Martin Salm & Job loss does not cause ill health & 08 \\
\hline $164-08$ & $\begin{array}{l}\text { Martin Salm, Daniel } \\
\text { Schunk }\end{array}$ & $\begin{array}{l}\text { The role of childhood health for the inter- } \\
\text { generational transmission of human capital: } \\
\text { Evidence from administrative data }\end{array}$ & 08 \\
\hline $165-08$ & Christina Benita Wilke & $\begin{array}{l}\text { On the feasibility of notional defined contribution } \\
\text { systems: The German case }\end{array}$ & 08 \\
\hline $166-08$ & $\begin{array}{l}\text { Alexander Ludwig } \\
\text { Michael Reiter }\end{array}$ & $\begin{array}{l}\text { Sharing Demographic Risk - Who is Afraid of } \\
\text { the Baby Bust? }\end{array}$ & 08 \\
\hline 167-08 & $\begin{array}{l}\text { Jürgen Maurer } \\
\text { André Meier }\end{array}$ & $\begin{array}{l}\text { Smooth it Like the "Joneses?" Estimating Peer- } \\
\text { Group Effects in Intertemporal Consumption } \\
\text { Choice }\end{array}$ & 08 \\
\hline 168-08 & $\begin{array}{l}\text { Melanie Lührmann } \\
\text { Jürgen Masurer }\end{array}$ & $\begin{array}{l}\text { Who wears the trousers? A semiparametric } \\
\text { analysis of decision power in couples }\end{array}$ & 08 \\
\hline $170-08$ & Jürgen Maurer & $\begin{array}{l}\text { Who has a clue to preventing the flu? } \\
\text { Unravelling supply and demand effects on the } \\
\text { take-up of influenza vaccinations }\end{array}$ & 08 \\
\hline $171-08$ & $\begin{array}{l}\text { Johannes Binswanger } \\
\text { Daniel Schunk }\end{array}$ & $\begin{array}{l}\text { What Is an Adequate Standard of Living } \\
\text { during Retirement? }\end{array}$ & 08 \\
\hline
\end{tabular}

